\title{
ERRATUM
}

\section{Erratum to: Key points on Zika infection for the intensivist}

\author{
Fernando A. Bozza ${ }^{1 *}$ and Beatriz Grinsztejn²
}

C 2016 Springer-Verlag Berlin Heidelberg and ESICM

\section{Erratum to: Intensive Care Med DOI 10.1007/s00134-016-4378-4}

Owing to an error in the manuscript supplied for publication, the surname of the second author was spelt incorrectly in this article as originally distributed. The correct spelling is as shown here; the article has been modified accordingly.

\section{Author details}

${ }^{1}$ Intensive Care Lab, Instituto Nacional de Infectologia Evandro Chagas (INI), Fundação Oswaldo Cruz (FIOCRUZ), Av. Brasil 4365, Rio De Janeiro, RJ 21045-900, Brazil. ${ }^{2}$ HIV Lab, Instituto Nacional de Infectologia Evandro Chagas (INI), Fundação Oswaldo Cruz (FIOCRUZ), Rio De Janeiro, Brazil.

The online version of the original article can be found under doi:10.1007/s00134-016-4378-4.

Published online: 14 June 2016

\footnotetext{
*Correspondence: fernando.bozza@ini.fiocruz.br:

${ }^{1}$ Intensive Care Lab, Instituto Nacional de Infectologia Evandro Chagas

(INI), Fundação Oswaldo Cruz (FIOCRUZ), Av. Brasil 4365, Rio De Janeiro, RJ 21045-900, Brazil
}

Full author information is available at the end of the article

\section{Springer}

